\title{
Questões de Interdisciplinaridade: As Funções em Química
}

\author{
MANUEL A.P SEGURADO *
}

\begin{abstract}
Comecandu pela caracterizacion dos fenomenos quinicos e das leis quantilativas que lhos está associadas, realca-se 0 imporlante papel da nudelacáo matemática e reconhecese a falte de interdisciplinaridade no que concerne a interface Matenálica - Quimica. Salienlia-5e, por ouiro lado, a imporlancia das funcóes e a necessidade de conhecer com perfeito rigor as propricelades analíticas peculiares de cada classe de funcão anles de as utilizar na modelaçâ em Quimica ou em qualquer outro campo. Para concrefizar este aspecto recorre-se ao (aso das funcōes humogrâficas. recordando a sua aplicacau em diversos dominios.
\end{abstract}

\section{INTRODUÇÃO}

É bem sabido que a interdisciplinaridade (e também a intradisciplinaridade) são conceitos muito apregoados mas raramente praticados. Com efeito, são sobejamente conhecidas as situações aberrantes encontradas a par e passo na ligação das Ciências Naturais ou da Biologia à Química, bastando folhear os manuais ao dispor dos estudantes do Básico e do Secundário para perceber que os conceitos mais avançados e estritamente químicos são realmente dados em primeira mão no seio daquelas duas primeiras disciplinas para só mais tarde serem então "revisitados" em moldes mais sustentados, se bem que em geral a nível mais elementar, agora sim no âmbito da Química.

Esta situação de todos conhecida e aliás já abordada nas páginas deste Boletim [1] é manifestamente perniciosa à correcta aprendizagem das matérias, levando obrigatoriamente à memorização dos conceitos introduzidos antes do tempo e, o que ainda é mais grave, retirando todo o carácter de novidade, sempre tão salutar pela dinâmica que gera, aos assuntos quando estes voltarem a ser tratados de novo no local e tempo próprios.
O objectivo deste artigo, todavia, é o de chamar a atenção para um outro aspecto algo semelhante mas mais subtil, e que é o da relação da Matemática com as Físico-Químicas e em particular com a Química. Com efeito, a Matemática é em geral leccionada de forma abstracta sem qualquer ligação às demais ciências, em especial à Física e à Química, situação algo paradoxal quando é sabido que os grandes ramos da Matemática (o Cálculo Infinitesimal e o Cálculo Vectorial, por exemplo) nasceram precisamente no seio destas ciências! A situação de completo divórcio entre a Matemática e as demais disciplinas que era suposto servir é de tal maneira gritante que até está patente na própria simbologia utilizada: assim, por exemplo, os nossos colegas de matemática estão tão fechados sobre si próprios que nunca se deram conta de que o seu logaritmo natural (que eles notam como log) colide com a notação que tradicionalmente era reservada ao logaritmo decimal e que os seus próprios alunos, ao saírem da aula de Matemática e entrarem na de Química utilizarão, por exemplo, quando forem confrontados com o cálculo do $\mathrm{pH}$ de uma solução. Por seu turno, os nossos colegas de Química, nomeadamente os mais novos, que já tiraram os seus cursos na era das calculadoras e jamais manusearam uma tábua de logaritmos, provavelmente nunca se lembrarão de esclarecer os seus alunos da verdadeira razão pela qual grandezas tão profusamente utilizadas como o $\mathrm{pH}$ ou a absorvância (definidas há muitas décadas atrás!) recorrem tendencialmente ao logaritmo decimal no lugar do neperiano (em boa verdade o logaritmo mais simples e o logaritmo dos matemáticos por excelência!).

A excessiva teorização e o afastamento da realidade do discente não é apenas oriunda da Matemática como também surge de dentro dos próprios programas de Química (ou da interpretação que deles fazem os manuais escolares!). Repare-se com efeito, quão absurda é a pretensão de falar da equação de Schrödinger a alunos que não só não dispõem de qualquer aparelhagem matemática indispensável à compreensão dos conceitos subjacentes (funções definidas em $\mathrm{R}^{\mathrm{n}}$, funções de variável complexa, equações diferenciais com derivadas parciais, álgebra matricial, etc., etc.) e que porventura nem sequer conhecem as leis do movimento harmónico simples. É minha conviç̧ão que, no âmbito da Física e da Química, seria bem mais proveitoso em muitas situações evitar uma excessivo formalismo, recorrendo à via heurística e fazendo uso da intuição, reservando para o Ensino Superior, na altura própria e na posse das bases indispensáveis, a construção de modelos teóricos rigorosamente sustentados e o refinamento dos conceitos anteriormente introduzidos. Mas a recíproca também é verdadeira: há efectivamente muitos assuntos cujo tratamento quantitativo mais aprofundado poderia ser iniciado já a partir do $12 .^{\circ}$ ano com os conhecimentos de Análise Matemática de que os alunos estão munidos desde o ano anterior ou que estão a adquirir na altura (conceito de derivada, noção de declive, extremos relativos, estudo de funções, por exemplo) e que poderiam proveitosamente ser utilizados com a introdução de noções como a de capacidade tampão de uma solução reguladora de $\mathrm{pH}$ ou o estudo das curvas de titulação, ademais com o aliciante de mostrar a aplicabilidade de conceitos matemáticos ainda frescos e motivando assim o estudante no seu interesse pela disciplina de Matemática. Por outro lado, a própria forma como se processa a aprendizagem das matemáticas, isolando-a das outras disciplinas, faz com que a generalidade dos nossos estudantes tenham sérias dificuldades em aplicar conceitos matemáticos fora do contexto onde os estudaram. É bem conhecida a tradicional inépcia para calcular uma simples derivada quando as variáveis não são representadas pelas tradicionais letras $x$ e $y$, as únicas que eles desde sempre utilizaram. De igual modo, conceitos tão simples como o de função (aplicação definida em A e 
com valores em B), que se habituaram a manusear com facilidade no seio das matemáticas, e definiram como uma correspondência unívoca de A para B, geram também e com frequência algumas dificuldades aos estudantes na correcta interpretação do seu significado físico. Para motivar os alunos sobre este tema e lhes mostrar o papel das funções como instrumento de leitura dos fenómenos naturais, sugiro aqui um caminho idêntico ao preconizado pelo saudoso Professor Sebastião e Silva [2], o grande introdutor entre nós das chamadas "Matemáticas Modernas", e que tanto se preocupou em tornar atraente esta disciplina, mostrando de forma simples a sua utilidade nos mais diversos domínios.

\section{FUNÇÕES E LEIS QUANTITATIVAS}

Se olharmos o mundo que nos rodeia, imediatamente nos daremos conta de que as propriedades dos seres materiais se encontram em perpétua mutação, variando no espaço e no tempo. E não será preciso procurar muito para encontrarmos exemplos dessa extraordinária mutabilidade que caracteriza o nosso próprio Universo. Assim, são variáveis o volume e a temperatura de um corpo, a forma de uma nuvem, a cor do céu, a altura do Sol acima do horizonte, o nível das águas no fluxo e refluxo das marés, a pressão atmosférica num dado lugar, a declinação magnética terrestre, a intensidade de uma fonte luminosa, o peso e a altura de uma pessoa ou a sua tensão arterial, o número de germes de uma colónia bacteriana, a população de uma cidade, a inflação, o desemprego ou a cotação da moeda de um determinado país, etc., etc.

Também as variações observadas podem ser mais ou menos rápidas, mais ou menos profundas. Assim, enquanto o movimento de precessão dos equinócios (um dos catorze principais movimentos do nosso planeta) tem um período longo de 260 séculos (originando o deşlocamento dos pólos celestes e arrastando consigo uma mudança nas estrelas circumpolares), uma estalactite poderá formar-se ao longo de anos por depósito lento de carbonato de cálcio proveniente das águas circulantes, uma bactéria pode dividirse em menos de vinte minutos sintetizando nesse curto período de tempo o seu próprio peso de material celular, e, no extremo oposto, um mesão $\pi^{\circ}$ possui uma vida efémera de $8,3 \times 10^{-16}$ segundos [3]. É precisamente a estas transformações ténues ou profundas, lentas ou rápidas, que se reduzem afinal todos os fenómenos naturais (e não só os fenómenos físicos, químicos, biológicos, etc., como também os económicos, sociais e políticos).

Ora sendo o objectivo final da Ciência o estabelecimento de um quadro ordenado e explicativo dos fenómenos naturais, ocorre-nos perguntar como dissecar a Natureza para o conseguirmos.

Não pareceria tarefa fácil e não o tem sido efectivamente ao longo dos vários milénios em que o Homem se tem interrogado a seu respeito. Já os antigos filósofos gregos haviam reconhecido a dificuldade de descrever a Natureza em toda a sua profunda instabilidade. Assim, para a chamada Escola Jónica, a realidade, como a vida, seria na sua essência variação, movimento, que nenhuma regra poderia jamais traduzir. Eles viam a realidade tal como as águas de um rio, as quais não são, em cada ponto do seu curso, o que eram ou julgávamos ser momentos antes, imagem esta de um Universo ininteligível bem patente na célebre frase de Heráclito, o confuso (540480 a.C.): "Tu nunca te poderás banhar duas vezes no mesmo rio, porque sempre novas águas correm para $i^{\prime \prime}$.

Afortunadamente, no mundo dos fenómenos naturais muitos de entre eles estão sujeitos a leis, o que quer dizer que as propriedades intervenientes em tais fenómenos, ao variarem, fazem-no mantendo entre si uma relação sensivelmente constante; em muitos casos tal relação pode mesmo ser traduzida analiticamente mediante uma fórmula matemática, definindo-se desse modo aquilo a que se chama uma lei quantitativa. Ora numa lei quantitativa as propriedades relacionadas são grandezas e é então possível calcular a medida de uma delas, sempre que nos seja dado conhecer a medida da outra ou outras das quais ela depende. A primeira daquelas grandezas diz-se então função das segundas e a relação que liga as variáveis em presença é denominada uma relação funcional. Deste modo, para analisarmos os fenómenos em geral e os químicos em particular, teremos pois que procurar na amálgama de variações que eles comportam, precisamente o que não muda ao longo de todas essas variações e que é, ao fim e ao cabo, a relação funcional que liga entre si as variáveis em jogo. Assim, no decurso de uma titulação ácido - base a concentração (actividade) de ião hidrónio pode aumentar (ou diminuir) enormemente (alguns milhares de milhões de vezes!), enquanto a concentração (actividade) de ião hidróxido varia em sentido contrário. Contudo, há algo que permanece, que não muda, e que é precisamente a relação expressa pela conhecida fórmula

$$
\mathrm{a}_{\mathrm{H}}+\cdot \mathrm{a}_{\mathrm{OH}^{-}}=\mathrm{K}_{\mathrm{w}}
$$

onde as duas variáveis em jogo são inversamente proporcionais e $K_{\mathrm{w}}$ é constante a cada temperatura.

\section{IDENTIFICAÇÃO DAS FUNÇÕES}

A matematização ou modelação matemática dos problemas em química requer cada vez mais, e em especial nos campos da Química-Física e da Química Analítica, uma boa preparação dos nossos estudantes numa gama cada vez mais vasta de técnicas matemáticas e computacionais associadas à moderna Quimiometria. Diversos autores [4,8], desde há muito que se têm preocupado com as bases matemáticas indispensáveis para a Química e das dificul- 
dades encontradas, quer a nível elementar, quer a nível avançado, evidenciando o facto de que o problema não é só nosso. Em artigo recente [9], é reconhecida a ausência de interdisciplinaridade no que concerne à interface Matemática - Química, propondo-se os autores fomentar essa integração de conhecimentos relacionando explicitamente o modelo químico utilizado com a correspondente função tal como ela é apresentada nos livros de Matemática. Com efeito, da mesma forma que para representarmos as grandezas recorremos aos números (que exprimem as suas medidas) igualmente utilizamos as funções na tradução das leis quantitativas que regem os fenómenos naturais, e as quais relacionam por seu turno as medidas das grandezas envolvidas e portanto os números, mediante fórmulas bem definidas. Assim, é tão absurdo querer construir um dado modelo químico sem conhecer perfeitamente as funções matemáticas que lhe servem de suporte, como seria caricato pretender medir uma grandeza que não fosse múltipla da unidade sem conhecer os números fraccionários e as suas propriedades.

O papel desempenhado pelas hipérboles em Química [9] e o saber identifica-las em diversas áreas, como é o caso da cinética enzimática referido pelos autores, é de facto extremamente importante; mas mais do que saber de que curva se trata, é preciso efectivamente conhecer com perfeito rigor as propriedades analíticas peculiares desta classe de funções antes de as querer utilizar em química ou em qualquer outro campo. Aliás, a situação aqui referida não será porventura única, ocorrendo com mais frequência do que se possa pensar. Exemplificando, e só para não sairmos deste tema, provavelmente muitos estudantes, no âmbito dos seus estudos em cromatografia, nunca se aperceberam que a célebre equação de Van Deemter [10] que traduz a dependência entre $h=$ HETP (altura equivalente a um prato teórico) e a velocidade linear de fluxo, $u$, a qual assume a forma

$$
h=A+\frac{B}{u}+C u
$$

é, ela própria, uma hipérbole.

Em minha opinião um estudo completo das funções pela via habitual da Análise (domínio, contradomínio, pontos de intersecção com os eixos coordenados, extremos, assimptotas, periodicidade, simetrias, etc.) deve sempre preceder o estudo de qualquer modelo químico que as vá utilizar. Assim, ou os conceitos matemáticos envolvidos já foram dados a montante do curso e devem ser minuciosamente recordados, ou ainda não foram introduzidos e deverão então sê-lo, caso isso seja possível, na altura em que os estudos em química ou em qualquer outra área o requeiram; caso tal não seja viável por se revelarem muito extensos e complexos os conceitos matemáticos subjacentes, é preferível então guardar para uma melhor oportunidade a abordagem do tema em questão.

\section{AS FUNÇÕES HOMOGRÁFICAS}

A propósito da cinética de Michaelis-Menten no contexto das hipérboles em Química [9], as funções envolvidas na conhecida relação

$$
\mathrm{v}=\frac{\mathrm{V}_{\max }[\mathrm{S}]}{[\mathrm{S}]+\mathrm{K}_{\mathrm{M}}}
$$

pertencem à classe das funções homográficas. Com efeito, uma função homográfica (ou bilinear) $f$, é toda a função fraccionária da forma

$$
x \mathrm{f}(\mathrm{x})=\frac{\mathrm{ax}+\mathrm{b}}{\mathrm{cx}+\mathrm{d}}
$$

sendo $a, b, c, d$ números reais, tais que $a d \neq b c$ e cujo domínio é, como facilmente se reconhece, $\left.\mathrm{D}_{f}=\right]-\infty$, $-d / c[\cup]-d / c,+\infty[$. A função $f$ anulase para $x=-b / a$ e toma o valor $y=b / d$ para $x=0$, e sendo pois $\mathrm{A}(-b / \mathrm{a}, 0)$ e $\mathrm{B}(0, b / d)$ os pontos de intersecção da curva com o eixo das abcissas e das ordenadas, respectivamente.
A designação de funções hiperbólicas por vezes atribuída a estas funções com base na natureza das curvas que elas representam deve ser evitada, já que pode originar confusão com as verdadeiras funções hiperbólicas, tais como

$$
\sinh x=\frac{e^{x}-e^{-x}}{2} \text { e } \cosh x=\frac{e^{x}+e^{-x}}{2}
$$

estabelecidas por analogia com as funções circulares e também elas presentes em diversas áreas da Química. Com efeito, da mesma forma que identificamos as linhas trigonométricas das funções co-seno e seno com a abcissa e ordenada da circunferência de raio unitário $x^{2}+y^{2}=1$, também de igual modo é possível interpretar ( $\cosh u, \sinh u$ ) como um ponto genérico do ramo direito da hipérbole de equação $x^{2}-y^{2}=1$, sendo pois esta a razão do seu nome [11].

Regressando à função homográfica e calculando a sua derivada encontramos

$$
f^{\prime}(x)=\frac{a d-b c}{(c x+d)^{2}}
$$

Atendendo a que por hipótese $a d-b c \neq 0$, uma função homográfica deverá ser estritamente crescente ou decrescente nos intervalos $]-\infty$, $-d / c[$ e $]-d / c,+\infty[$ em que é definida, consoante o numerador $a d$ - $b c$ for positivo ou negativo e não pode evidentemente apresentar máximos ou mínimos relativos. Calculando os limites nos extremos do domínio e à esquerda e à direita do ponto $x=-d / c$ (que anula o denominador), facilmente o aluno concluirá pela existência de uma assimptota horizontal de equação $y=a / c$ e outra vertical de equação $x=-d / c$. Nesta altura é também já fácil reconhecer que o contradomínio da função (o domínio da função inversa) é o conjunto $\left.\mathrm{D}_{f}^{-1}=\right]-\infty, \mathrm{a} / \mathrm{c}[\cup] \mathrm{a} / \mathrm{c},+\infty[$.

Reescrevendo a nossa equação na forma $c x y-a x+d y-b=0$ e comparando-a com a forma geral das cónicas $A x^{2}+B x y+C y^{2}+D x+E y+F$ $=0$ facilmente se comprova que o discriminante $B^{2}-4 A C$ é igual a $c^{2}>0$, 
justificando o facto conhecido de a imagem geométrica da função homográfica ser uma hipérbole; em particular, por possuir duas assimptotas perpendiculares entre si, pertence à categoria das hipérboles rectangulares (ou equiláteras) e o ponto $\mathrm{C}(-d / c, a / c)$ onde as assimptotas se intersectam é o centro de simetria da hipérbole. Por último, o sentido da concavidade dos dois ramos de hipérbole definidos nos intervalos ]- $\infty$, $-d / c[$ e $]-d / c,+\infty[$ pode ser facilmente retirado em cada caso concreto do sinal da segunda derivada, a qual vem dada pela expressão:

$$
f^{\prime \prime}(x)=\frac{2 c(b c-a d)}{(c x+d)^{3}}
$$

Antes ainda de abordar a cinética enzimática é útil dar aos alunos um exemplo concreto e simples de função homográfica do tipo da que vem expressa na equação

$$
\mathrm{v}=\frac{\mathrm{v}_{\text {max }}[\mathrm{S}]}{[\mathrm{S}]+\mathrm{K}_{\mathrm{M}}}
$$

que, como se observa, se reduz neste caso a uma função homográfica "incompleta", com $y=v, x=[S], a=$ $v_{\max }>0, b=0, c=1$ e $d=K_{\mathrm{M}}>0$. ção

Tomando como exemplo a fun-

$$
x y=\frac{4 x}{x+2}
$$

que é precisamente desta forma, facilmente os alunos procederão ao seu estudo de acordo com a metodologia atrás indicada e esboçarão o gráfico respectivo (Fig. 1).

O domínio será agora $\mathrm{D} f=]-\infty$, $-2[\cup]-2,+\infty[$, o contradomínio ]- $4[\cup] 4,+\infty[$, enquanto as assimptotas horizontal e vertical são as rectas de equações $y=4$ e $x=-2$.

Pelo facto de se ter aqui $b=0$, virá neste caso

$\mathrm{A} \equiv(-b / a, 0) \equiv \mathrm{B} \equiv(0, b / d) \equiv 0(0,0)$

e o ramo inferior da hipérbole passa obrigatoriamente pela origem, da mesma forma que o centro de simetria
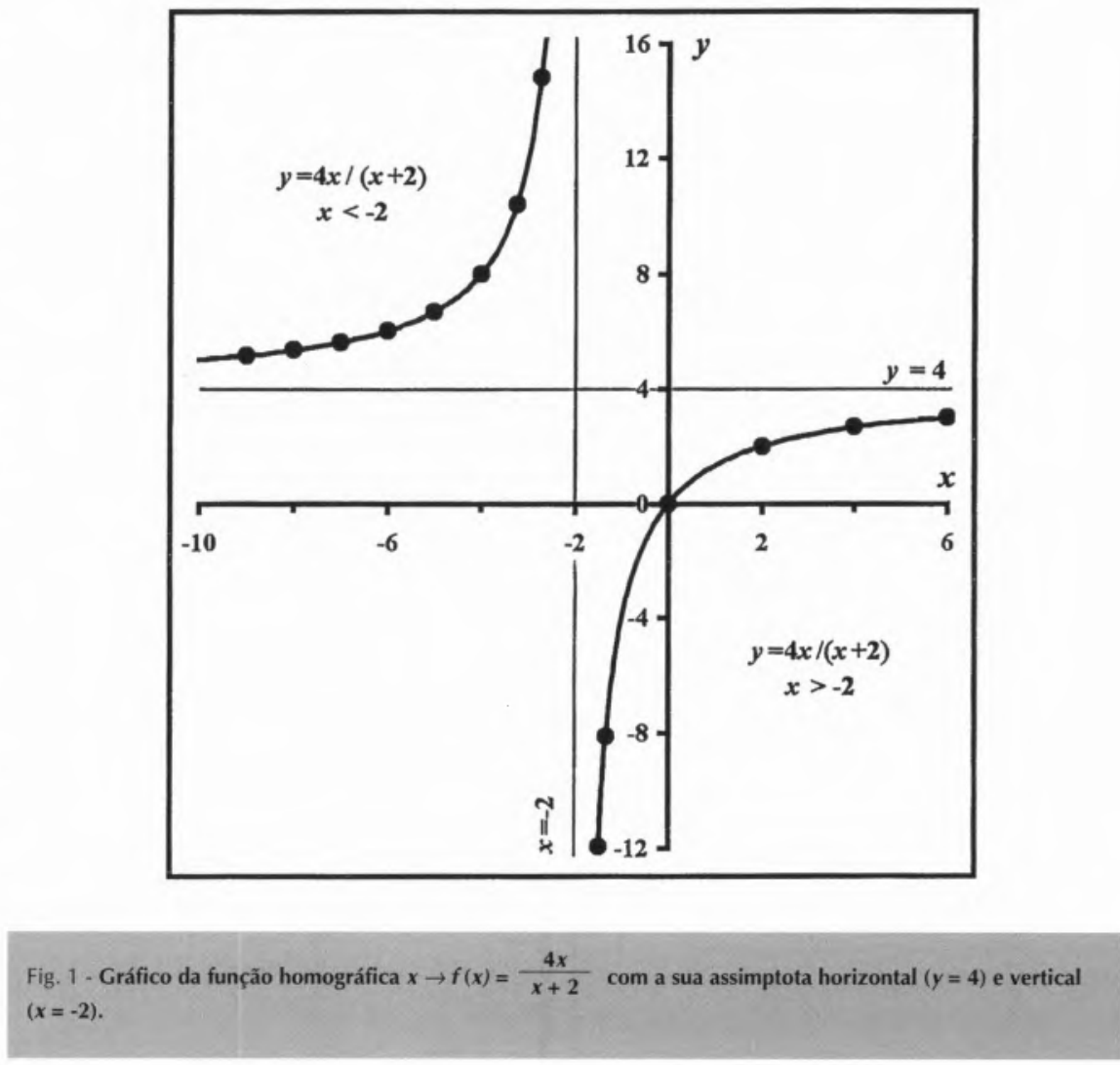

da curva é aqui $C(-d / c, a / c) \equiv(-2,4)$.

Finalmente, verifica-se por observação do gráfico ser ele côncavo

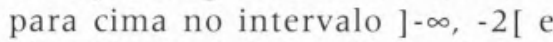
côncavo para baixo no intervalo ]-2, $+\infty$ [, em perfeita concordância com o sinal da segunda derivada, que neste caso vem dada pela expressão

$$
y^{\prime \prime}=-\frac{16}{(x+2)^{3}}
$$

e a qual é positiva para $x<-2$ e negativa para $x>-2$.

Uma interessante propriedade apresentada pelas funções homográficas deste tipo consiste na sua "anamorfose linear" mediante a simples substituição das variáveis actuais pelos seus inversos. Com efeito, se substituirmos a correspondência entre a variável $x$ e a variável $y$ (que aqui desempenham o mesmo papel que as variáveis [S] e $v$ na equação de Michaelis-Menten) pela correspondência entre os recíprocos dessas mesmas variáveis, obteremos uma função linear mais fácil de manusear graficamente.

Posto isto, consideremos então a função (8) dada e façamos nela aquela substituição, permutando $y$ com $1 / y$ e $x \operatorname{com} 1 / x$. Virá assim:

$$
\begin{aligned}
& \frac{1}{y}=\frac{x+2}{4 x} \Leftrightarrow \frac{1}{y}=\frac{1}{2} \cdot \frac{1}{x}+\frac{1}{4} \\
& \text { ou } \quad y^{-1}=\frac{1}{2} \cdot x^{-1}+\frac{1}{4}
\end{aligned}
$$

que é a equação de uma recta não vertical da forma $y=m x+b$ cujo declive é $m=1 / 2$ [quociente do termo independente do denominador $(d=2)$ pelo coeficiente de $x$ no numerador da função original $(a=4)]$ e a ordenada na origem é igual a $1 / 4$ (inverso do coeficiente de $x$ no numerador da função dada).

Da minha experiência de mais de vinte anos como professor em cursos introdutórios de química e de matemática aplicada na minha Faculdade, tenho constatado que desa- 
fiando os alunos a manusearem este exemplo simples de função homográfica através de transformações de equivalência sugeridas por si mesmos, eles têm conseguido com uma enorme facilidade descobrir esta e diversas outras transformações similares, tendo tido o prazer de observar que em muitos casos acabaram por redescobrir formas de linearização clássicas bem conhecidas $[12,13]$, como as que a seguir se transcrevem:

a) Representação de Lineweaver e Burk:

$$
\frac{1}{\mathrm{~V}}=\frac{1}{\mathrm{~V}_{\max }}+\frac{\mathrm{K}_{\mathrm{M}}}{\mathrm{V}_{\max }} \cdot \frac{1}{[\mathrm{~S}]}
$$

b) Representação de Hanes e Woolf:

$$
\frac{[\mathrm{S}]}{\mathrm{V}}=\frac{\mathrm{K}_{\mathrm{M}}}{\mathrm{V}_{\max }}+\frac{1}{\mathrm{~V}_{\max }}
$$

c) Representação de Eadie e Hofstee:

$$
\mathrm{V}=\mathrm{V}_{\max }-\mathrm{K}_{\mathrm{M}} \cdot \frac{\mathrm{V}}{[\mathrm{S}]}
$$

d) Representação de Scatchard:

$$
\frac{\mathrm{V}}{[\mathrm{S}]}=\frac{\mathrm{V}_{\max }}{\mathrm{K}_{\mathrm{M}}}-\frac{1}{\mathrm{~K}_{\mathrm{M}}} \cdot \mathrm{v}
$$

Esta é também uma boa oportunidade para alertar desde logo os estudantes para alguns dos inconvenientes destas transformações que, apesar de perfeitamente legítimas do ponto de vista puramente algébrico, o não são em perfeito rigor em termos estatísticos no que concerne aos ajustamentos efectuados, por conferirem pesos diferentes às variáveis intervenientes. Assim, a primeira das representações indicadas (Lineweaver-Burk), uma das mais populares, apresenta o inconveniente de que pequenos erros na velocidade inicial $v$ conduzem a grandes erros em $1 / \mathrm{v} \mathrm{e}$ daí a grandes erros em $K_{\mathrm{M}}$ e $v_{\max }$; as outras representações têm como ponto fraco a presença de uma mesma variável em ambos os membros ou a coexistência das duas no mesmo membro. Apesar de tudo, revelam-se muito úteis para uma primeira visualização dos resultados cinéticos e para diagnóstico de diversas situações como as relativas, p. ex... a enzimas que requerem mais do que um substrato. Por seu turno, elas representam uma via simples para a determinação de estimativas provisórias dos parâmetros $K_{M}$ e $v_{\max }$ a utilizar nos modernos métodos de ajuste não linear.

\section{A INTEGRAÇ̃̃O DOS CONHECIMENTOS}

Sem ser adivinho, atrevo-me a pensar que muitos colegas estarão a dizer nesta altura que para alunos de química isto é já matemática em demasia!

Mas a questão é precisamente essa! Há de facto o preconceito de que a Química (com as honrosas excepções da Mecânica Estatística, da Mecânica Quântica e de alguns outros ramos da Química-Física!) é uma parente pobre que se limita a utilizar, do vasto arsenal matemático de que dispõe, algumas proporções, equações do $1 .^{\circ}$ e do $2 .^{\circ}$ grau, logaritmos e pouco mais. Ao propor que se faça uma revisão das funções homográficas e das suas propriedades antes do estudo da cinética enzimática (enquadrada numa cadeira de Bioquímica), reservando-lhe uma parte de uma aula prática, por exemplo, mais não faço do que sugerir algo que por certo se reflectirá positivamente na correcta aprendizagem do tema em questão. Por outro lado, uma tal atitude por parte do docente assume o papel pedagógico de que no futuro, qualquer outro tema deverá ser precedido de uma revisão semelhante feita desta vez pelo aluno, que deverá colocar contudo as dúvidas que lhe foram suscitadas nessa preparação. Tal ponto de vista poderá mais facilmente ser ponderado com a ajuda de um exemplo hipotético mas não inverosímil nas suas conclusões. Imaginemos que o manual de Bioquímica utilizado pelos estudantes se apresentava gralhado e afirmava que a curva de Michaelis-Menten era uma parábola ao invés de uma hipérbole. Quantos alunos se aperceberiam do erro? Da minha experiência de ensino estou em crer que muito poucos! Mas curiosamente, grande número deles terão sido ou ainda são bons alunos de Matemática e aprenderam das noções de Geometria Analítica que trouxeram do Secundário (ou até já ampliadas na Faculdade) que o sinal do discriminante $B^{2}-4 A C$ pode ser comodamente utilizado para identificar a natureza da cónica [elipse $(<0)$; parábola $(=0)$; hipérbole $(>0)$ ], ou na pior das hipóteses recordariam, pelo menos, que uma parábola jamais pode ter assimptotas. De igual modo, o facto da velocidade inicial $v$ se aproximar assimptoticamente de $v_{\max }$ quando aumenta a concentração de substrato $[S]$ (basta calcular a razão entre os coeficientes dos termos do $1 .^{\circ}$ grau do numerador e do denominador) ou a constatação de que a assimptota vertical da hipérbole é a recta de equação $[S]=-K_{M}$ (basta mentalmente anular o denominador), são noções que na generalidade dos casos são simplesmente memorizadas sem que o aluno esboce sequer uma tentativa de justificar esses factos analiticamente. Entretanto, podemo-nos interrogar das razões que levam a que isto aconteça. A explicação é simples. Como a Matemática sempre foi estudada isoladamente, tanto os conhecimentos aí adquiridos como os oriundos de outras áreas, sempre se acumularam em conjuntos disjuntos, verdadeiros compartimentos estanques de difícil interligação de forma expedita pelo aluno. Aliás, o próprio sistema de avaliação (pontos modelo, perguntas normalizadas, problemas tipo, etc.) favorece este estado de coisas, pois é mais fácil debitar quase instantaneamente algo que se memorizou (ainda que a curto prazo) do que procurar a justificação numa sequência de raciocínios. 
É claro que se o modo como os nossos colegas das Matemáticas (e não só no Básico ou no Secundário, mas também na Universidade) veiculam as matérias não é o mais propício a estabelecer a ponte com as demais disciplinas (este aspecto já foi aliás aflorado neste Boletim [14]), nós, docentes de Química, não estamos também isentos de culpas em relação a este estado de coisas. Afinal, porque é que não somos nós a servir de elo de ligação e a fazer mais uso dos conhecimentos matemáticos dos nossos alunos? Porque é que nós, por exemplo, sabendo que os nossos estudantes do $12 .^{\circ}$ ano acabaram de fazer o estudo das funções, não aplicamos esses mesmos conhecimentos ao estudo das curvas de titulação em alternativa à simples memorização daquelas que encontram nas páginas do livro e que nem sequer foram sugeridas pela experiência já que muito provavelmente tais ensaios nunca foram realizados no laboratório? Por último, por que razão os nossos programas de Matemática e de Química não aproveitam essas sinergias e articulam melhor as matérias das áreas intimamente ligadas?

\section{DOMÍNIO DAS FUNÇÕES E LEIS QUANTITATIVAS}

No artigo acima referido [9], os autores procuraram visualizar o carácter hiperbólico dos gráficos encontrados nas cinéticas de MichaelisMenten incluindo valores negativos das concentrações de substrato (apesar de desprovidas de significado físico!) a fim de mostrar aos estudantes o outro ramo da hipérbole, localizado no $2 .^{\circ}$ quadrante.

Ainda que sugestivo, penso não ser este, do ponto de vista didáctico, o melhor caminho para abordar este aspecto. De facto, o aluno de Química que estuda cinética enzimática não é propriamente um principiante em Álgebra e Cálculo e deverá estar munido do poder de abstracção que lhe permita ligar o seu modelo à função matemática que lhe está associa-

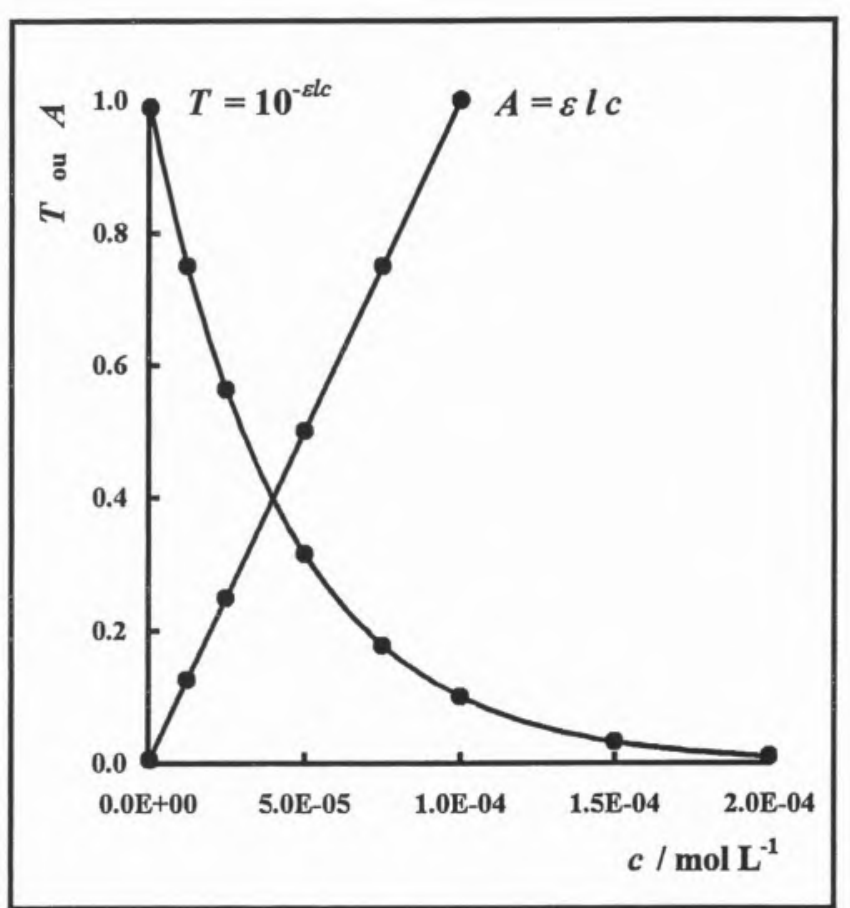

Fig. 2 - Representação gráfica da lei de Beer-Lambert (com $\varepsilon=1.00 \times 10^{4} \mathrm{~L} \mathrm{~mol}^{-1} \mathrm{~cm}^{-1} \mathrm{e} I=1 \mathrm{~cm}$ ) em termos da transmitância (exponencial decrescente $T=10^{-k}$ ) e da absorvância (recta $A=\varepsilon l c$ ).

da e saber distinguir entre o domínio natural dessa função (real de variável real) e o domínio próprio da relação que traduz a lei quantitativa em estudo, em geral mais restrito do que o primeiro.

Assim, por exemplo, reportando-nos à conhecida lei de Beer-Lambert, cuja expressão é, recordemo-lo,

$$
I=I_{0} \cdot 1 \sigma^{\varepsilon 1 c}
$$

onde $I_{\mathrm{O}}$ e $I$ representam as intensidade dos feixes incidente e emergente, respectivamente, $l$ a espessura atravessada, $\varepsilon$ a absortividade da espécie absorvente e $c$ a sua concentração na solução, e atendendo a que a transmitância vem definida por $T=I / I_{\mathrm{O}}$, podemos reescrever a equação (17) pondo

$$
\mathrm{T}=1 \sigma^{\varepsilon 1 \mathrm{c}}
$$

ou ainda

$$
\mathrm{A}=\varepsilon \mathrm{lc}_{\mathrm{C}}
$$

sendo $A=-\log T$, a absorvância da solução.

Ora neste caso a função

$$
C \mathrm{\Gamma}=1 \sigma^{\varepsilon \mathrm{lc}}
$$

cujo gráfico vai representado na Fig. 2 para $l=1 \mathrm{~cm}$ é do tipo $y=a^{-k x}$ (com $a, k \in \mathrm{R}^{+}$), exponencial decrescente que, entendida como função real de variável real em toda a sua generalidade, terá como imagem geométrica a curva teórica definida de $-\infty$ a $+\infty$ que intersecta o eixo das ordenadas no ponto $(0,1)$ e tem como assimptota horizontal o eixo das abcissas. Mas é evidente que são desprovidos de sentido físico os pontos da curva situados no $2 .^{\circ}$ quadrante, possuidores de ordenadas superiores a 1. Com efeito, não só não se deverão considerar por razões óbvias concentrações negativas, como também não se tem em geral $T=I / I_{0}>1$, já que nas situações ordinárias $I$ não assume valores superiores a $I_{0}$.

Surge pois também aqui a necessidade de considerar apenas uma 
restrição da função considerada a um intervalo de concentrações para o qual as grandezas tenham significado físico e a lei seja aplicável. Na realidade, o domínio da nossa restrição não é o intervalo $[0,+\infty[$ como se poderia admitir com base na simples rejeição dos valores negativos da variável $c$. Com efeito, uma observação um pouco mais atenta da situação facilmente nos permite concluir que na realidade as concentrações não podem ultrapassar um determinado valor; basta pensar que a concentração do soluto (à parte os limites de solubilidade) não pode ir além da que corresponde à substância pura, para já não falar do facto conhecido de que a lei de Beer-Lambert só é rigorosamente válida para soluções diluídas.

De forma idêntica, a linearização daquela mesma curva através da relação $A=\varepsilon l c$, que equivale à construção de um gráfico semi-logarítmico, conduz a uma função linear da forma $y=m x+b, \operatorname{com} b=0$ (Fig. 2), e que é pois, do ponto de vista matemático, a equação de uma recta não vertical que passa pela origem comum dos eixos coordenados e está definida para todo o $x \in \mathrm{R}$. Mas relativamente à lei quantitativa a que ela serve de suporte, está contudo definida apenas num intervalo $\mathrm{I} \subset \mathrm{R}_{\mathrm{o}}{ }^{+}$, cujo limite superior é o das concentrações para as quais é válida a lei de Beer-Lambert aplicada à espécie absorvente considerada. Em suma, o que se deverá fazer em todos os casos e em primeiro lugar é o estudo teórico completo da função matemática que é utilizada e só depois, com base na própria natureza da variável independente, considerar uma apropriada restrição daquela função ao nosso modelo.

\section{APLICAÇÕES DAS FUNÇÕES HOMOGRÁFICAS}

Ainda a respeito das funções homográficas é importante que se diga que o seu estudo completo. como o que foi acima efectuado é extremamente importante e o seu conhecimento tão útil em química como o do trinómio do $2 .^{\circ}$ grau, o das funções trigonométricas, exponenciais ou logarítmicas. Com efeito, para além dos exemplos da cinética enzimática, adsorção (isotérmicas de Langmuir), extracção por solventes e associação de ligandos a macromoléculas) referidos por Underwood [15], a função homográfica está tão amplamente difundida em tantas áreas da Química que é extremamente difícil fazer uma enumeração exaustiva de todas as situações conhecidas. Apenas no campo da Química Analítica já os exemplos disponíveis são incontáveis. Assim, quando a propósito das reacções ácido-base como as que envolvem o ácido monoprótico HA

$\mathrm{HA}(a q)+\mathrm{H}_{2} \mathrm{O}(l) \rightleftarrows \mathrm{A}^{-}(a q)+\mathrm{H}_{3} \mathrm{O}^{+}(a q)$

ou as de precipitação argentimétrica como

$\mathrm{Ag}^{+}(a q)+\mathrm{Cl}^{-}(a q) \rightleftarrows \mathrm{AgCl}(s)$

escrevemos as relações bem conhecidas

$$
\begin{gathered}
{[\mathrm{HA}]=\frac{c h}{h+K_{\mathrm{a}}},\left[\mathrm{A}^{-}\right]=\frac{K_{\mathrm{a}} c}{h+K_{\mathrm{a}}},\left[\mathrm{OH}^{-}\right]=\frac{K_{\mathrm{w}}}{h}} \\
\alpha_{\mathrm{HA}}=\frac{h}{h+K_{\mathrm{a}}}, \quad \alpha_{A^{-}}=\frac{K_{\mathrm{a}}}{h+K_{\mathrm{a}}}
\end{gathered}
$$

ou

$$
\left[\mathrm{Ag}^{+}\right]=K_{\mathrm{ps}} /\left[\mathrm{Cl}^{-}\right]
$$

onde pusemos, por questão de simplicidade, $\left[\mathrm{H}_{3} \mathrm{O}^{+}\right]=h$ e os demais símbolos têm o significado habitual, todas as funções envolvidas.

$$
\begin{aligned}
f_{1}: h \mapsto[\mathrm{HA}], f_{2}: h \mapsto[\mathrm{A}], f_{3}: h \mapsto[\mathrm{OH}], f_{4}: h \mapsto \alpha_{\mathrm{HA}} \\
f_{5}: h \mapsto \alpha_{A^{-}}, f_{6}:[\mathrm{Cl}] \mapsto\left[\mathrm{Ag}^{\prime}\right]
\end{aligned}
$$

são, como é fácil reconhecer, casos particulares da função homográfica estudada acima.

O próprio uso de um gráfico de Gran [16] para a determinação do ponto de equivalência em titulações potenciométricas, cujas reais vantagens têm sido postas em evidência por diversos autores [17-19], assentam numa função homográfica.

Com efeito, reportando-nos por questão de simplicidade ao caso da titulação de um ácido forte com uma base forte, ter-se-á, até às imediações do ponto de equivalência,

$$
\left[\mathrm{H}^{+}\right]=\frac{\mathrm{C}_{\mathrm{a}} \mathrm{V}_{\mathrm{a}}-\mathrm{C}_{\mathrm{b}} \mathrm{V}_{\mathrm{b}}}{\mathrm{V}_{\mathrm{a}}+\mathrm{V}_{\mathrm{b}}}
$$

onde $C_{\mathrm{a}}$ e $V_{\mathrm{a}}$ representam a con centração e o volume do ácido e $C_{\mathrm{b}} \mathrm{e}$ $V_{\mathrm{b}}$ a concentração e o volume da solução da base usada como titulante.

Designando por $V_{\mathrm{e}}$ o volume de equivalência e substituindo $C_{\mathrm{a}} V_{\mathrm{a}}$ por $C_{\mathrm{b}} V_{\mathrm{e}}$, a equação (22) pode ser reescrita na forma

$$
\left[\mathrm{H}^{+}\right]=\frac{\mathrm{C}_{\mathrm{b}} \mathrm{V}_{\mathrm{e}}-\mathrm{C}_{\mathrm{b}} \mathrm{V}_{\mathrm{b}}}{\mathrm{V}_{\mathrm{a}}+\mathrm{V}_{\mathrm{b}}}
$$

ou ainda, pelo facto de ser $a_{\mathrm{H}+}=$ $10-\mathrm{pH}=\gamma \mathrm{H}+\left[\mathrm{H}^{+}\right]$e os eléctrodos de $\mathrm{pH}$ responderem à actividade e não à concentração hidroniónica, assumir o novo aspecto

$$
\begin{aligned}
& 10^{-\mathrm{pH}}=\frac{C_{\mathrm{b}} \gamma_{\mathrm{H}^{+}} V_{\mathrm{e}}-C_{\mathrm{b}} \gamma_{\mathrm{H}^{+}} V_{\mathrm{b}}}{V_{\mathrm{a}}+V_{\mathrm{b}}} \Leftrightarrow \\
& \Leftrightarrow 10^{-\mathrm{pH}}=\frac{C_{\mathrm{b}} \gamma_{\mathrm{H}^{+}}\left(V_{\mathrm{e}}-V_{\mathrm{b}}\right)}{V_{\mathrm{a}}+V_{\mathrm{b}}}
\end{aligned}
$$

que é mais uma vez uma função homográfica da forma

$$
y=\frac{a x+b}{c x+d}
$$

com $y=10-\mathrm{pH}, x=V_{\mathrm{b}}, a=-C_{\mathrm{b} \gamma \mathrm{H}+}$, $b=C_{\mathrm{b} \gamma \mathrm{H}+} V_{\mathrm{e}}, c=1$ e $d=V_{\mathrm{a}}$, a qual pode ser facilmente linearizada, pondo

$$
\left(V_{\mathrm{a}}+V_{\mathrm{b}}\right) 10^{-\mathrm{pH}}=C_{\mathrm{b}} \gamma_{\mathrm{H}^{+}}\left(V_{\mathrm{e}}-V_{\mathrm{b}}\right)
$$

e construindo um gráfico de $Y=\left(V_{\mathrm{a}}\right.$ $\left.+V_{\mathrm{b}}\right) 10$ - $\mathrm{pH}$ versus $X=V_{\mathrm{b}}$, que conduz a uma recta que intersecta o eixo das abcissas para $X=V_{\mathrm{e}}$ (abcissa na origem). 
Como se constata, os exemplos das aplicações desta classe de funções em Química são numerosíssimos e até leis físicas simples bem conhecidas dos estudantes, tais como a lei de Boyle-Mariotte, definida por

$p V=$ const. $\quad \Leftrightarrow \quad p=$ const. $/ V \quad \Leftrightarrow \quad V=$ const. $/ p$

ou a lei de Jurin da ascensão capilar $h$ (directamente proporcional à tensão superficial $\gamma$ do líquido e inversamente proporcional ao raio $r$ da secção recta do tubo e à massa volúmica do líquido), expressa pela relação

$$
\mathrm{h}=2 \gamma / \mathrm{g} \rho \mathrm{r}
$$

estão associadas às funções $p(V), V(p)$ ou $h(r)$, que outra coisa não são do que casos particulares da função homográfica a que correspondem hipérboles equiláteras cujas assimptotas coincidem com os eixos coordenados.

Note-se contudo que, para lá das leis clássicas descritas e das relações frequentemente encontradas na rotina do cálculo em Química, as funções homográficas continuam a ser largamente utilizadas na investigação e na descoberta. Assim, ainda muito recentemente e no campo da Química Orgânica Física foi proposto [20-22] um novo modelo hiperbólico para as inter-relações meta-para em derivados do benzeno, associado a um aperfeiçoamento plurilinear da clássica equação de Hammett.

\section{CONCLUSÃO}

Do exposto se conclui, dada a ubiquidade das funções homográficas em Química, ser no mínimo estranho o desconhecimento por parte dos estudantes, tal como é salientado no artigo supracitado [9], das suas características analíticas, das curvas que representam e até do seu nome. Em boa verdade, quer na aprendizagem da Química, quer na investigação e na descoberta, a modelação dos problemas e a pesquisa de novas leis quantitativas não poderão ser cabalmente conseguidas sem um conhecimento profundo das propriedades das funções utilizadas, aplicando-se aqui com perfeita acuidade a célebre frase de Louis Pasteur (1822-1895): "Dans les champs de l'observation le hasard ne favorise que les esprits préparés." * Centro de Electroquímica e Cinética
da Universidade de Lisboa
Faculdade de Farmácia, Av. das Forças Armadas,
1649-019 Lisboa, Portugal

\section{BIBLIOGRAFIA}

1. A. C. Cardoso, Bol. Soc. Port. Quím., 53 (1994) 6.

2. J. Sebastião e Silva, J. D. da Silva Paulo, Com pêndio de Álgebra, Tomo I, 6. ${ }^{\circ}$ Ano, Livraria Popular de Francisco Franco, Lisboa, 1963.

3. W.E. Burcham, M. Jobes, Nuclear and Particle Physics, Longman, 1997.

4. E. S. Swinbourne, P. D. Lark, J. Chem. Educ., 30 (1953) 570.

5. R. J. Tycodi, J. Chem. Educ., 59 (1982) 557.

6. T. Wang, J. Chem. Educ., 59 (1982) 592.

7. C. W. David, J. Chem. Educ., 72 (1995) 995.

8. R. W. Maatman, J. Chem. Educ., 72 (1995) 1089
9. R. A. Day, A. L. Underwood, J. Chem. Educ., 72 (1995) 597.

10. J. J. van Deemter, F. F. Zuiderweg, A. Klinkenberg, Chem. Eng. Sci., 5 (1956) 271.

11. M. A. P. Segurado, Biomatemática, Vol. II, Plátano Editora, Lisboa, 1980.

12. J. B. S. Haldane, K. G. Stern, Allgemeine Chemie der Enzyme, Steinkopff, Dresden \& Leipzig, 1932, p 119.

13. G. Scatchard, Ann. N. Y. Acad. Sci., 51 (1949) 660 .

14. J. A. M. Simões, Bol. Soc. Port. Quím., 56 (1995) 11.

15. A. L. Underwood, J. Chem. Educ., 61 (1984) 143.

16. G. Gran, Anal. Chim. Acta, 206 (1988) 111.

17. F. J. C. Rossotti, H. Rossotti, J. Chem. Educ., 42 (1965) 375.

18. L. M. Schwartz, J. Chem. Educ., 64 (1987) 947.

19. L. M. Schwartz, J. Chem. Educ,, 69 (1992) 879.

20. J. C. R. Reis, M. A. P. Segurado, J. D. G. de Oliveira, J. Phys.Org.Chem., 8 (1995) 5.

21. J. C. R. Reis, M. A. P. Segurado, J. D. G. de Oliveira, J. Phys.Org.Chem., 8 (1995) 671.

22. I. C. R. Reis, M. A. P. Segurado, J. D. G. de Oliveira, J. Phys.Org.Chem., 11 (1998) 495.

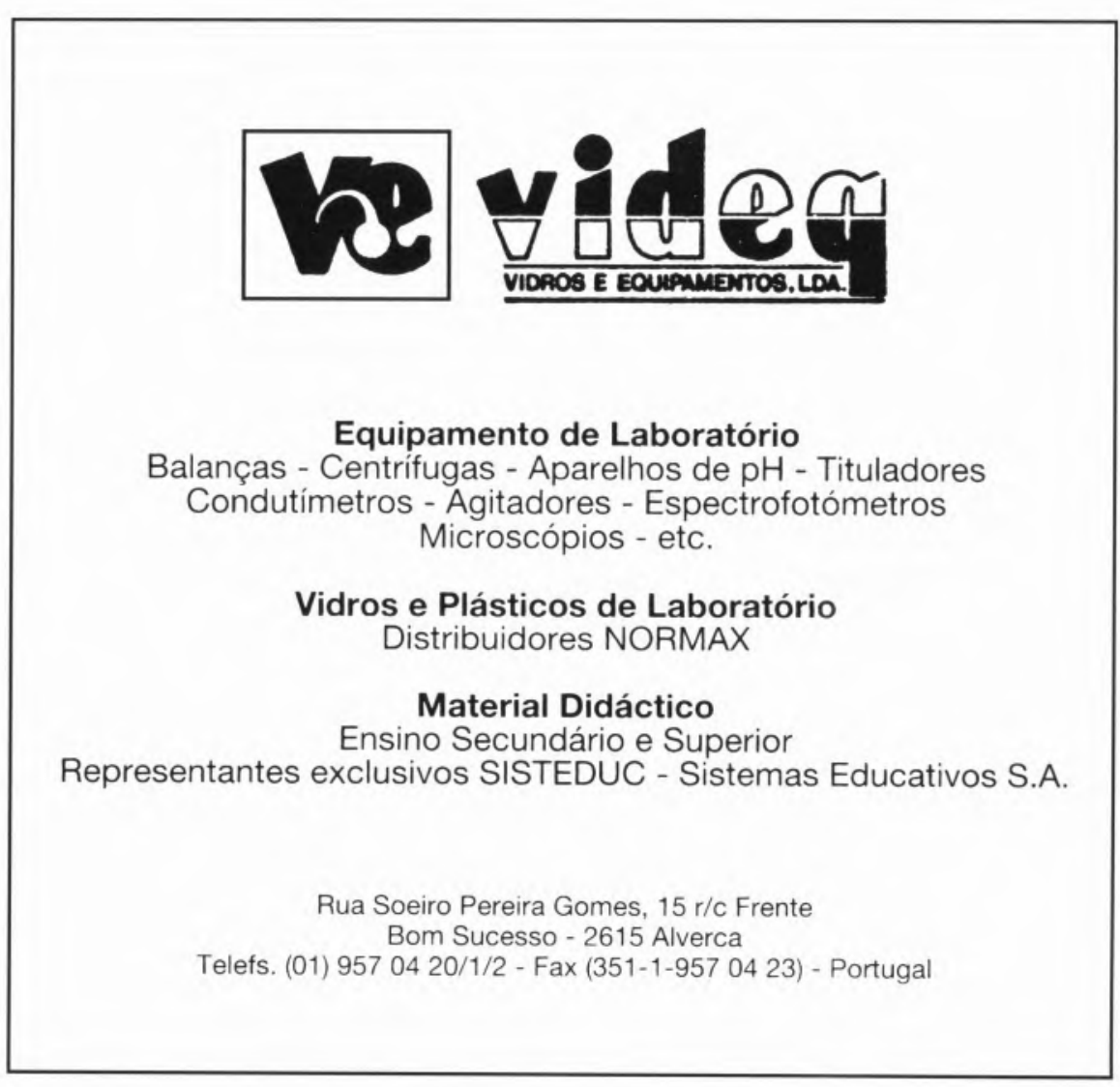

